\title{
CHIASMAL CROSSING DEFECTS IN DISORDERS OF BINOCULAR VISION
}

\author{
P. APKARIAN \\ Rotterdam, The Netherlands
}

The primary objectives of this brief overview are: (1) to introduce an unusual, naturally occurring malformation of the visual pathways in the form of a missing optic chiasm, i.e. non-decussating retinal-fugal fibre or achiasmatic syndrome $\mathrm{e}^{1-3}$ and (2) to discuss binocular function and dysfunction in the two major conditions of naturally occurring aberrant optic projections, albinism and newly discovered achiasmatic syndrome. In either of these inborn errors of visual pathway structure, retinal axons misproject at the locus of the optic chiasm, disrupting retinal-fugal projections, organisation and function throughout the visual pathways. In albinism, a preponderance of temporal retinal-fugal projections erroneously decussate at the optic chiasm. ${ }^{4-9}$ Within the primary retinal recipient target, the dorsal lateral geniculate nucleus (LGN), misrouted temporal retinal fibres misproject and misalign with normally decussating nasal retinal fibres of the same eye. As a result, for the albino mammal, regardless of albino genotype or phenotype, the medial segments of LGN layers representing a substantial portion of the ipsilateral visual field are mistakenly aligned with LGN layers of the opposite, contralateral field. Concomitant albino misprojections to auxiliary, subcortical visual pathways such as the superior colliculus, pulvinar and other retinal relays have also been identified and investigated. ${ }^{10-16}$

The abnormal albino or the achiasmatic visual field representation and corresponding anatomical projections have been referred to as misalignments in 'mirror reversal' or 'mirror symmetry' of left and right half visual space coordinates. ${ }^{3,17,18}$ The simplified schematic of Fig. 1 illustrates that retinotopic mapping within the functionally and eye segregated LGN laminae is severely disrupted in both albinism and achiasmatic syndrome. As also illustrated in Fig. 1 , opposite to the preponderance of decussating

Correspondence to: P. Apkarian, Department of Physiology I, Medical Faculty, Erasmus University, PO Box 1738, 3000DR Rotterdam, The Netherlands. Fax: +3110436 7594. e-mail: apkarian@fys1.fgg.eur.nl. temporal retinal fibres in albinism, in achiasmatic syndrome all nasal fibres fail to decussate at the optic chiasmal junction, which is, in fact, missing. In the achiasmatic condition, the misrouted nasal retinal fibres project to and misalign with projections of the temporal retina of the same eye. ${ }^{3}$ The result, as in albinism (but in reverse order and in a more complete fashion), is that nasal retinal fibres align with temporal retinal fibres from the same retina. For the achiasmatic condition, the entire visual field is represented in mirror-reversed order. How this mirror-reversed information in the achiasmatic condition is communicated to the visual cortex is under investigation in a pedigree of mutant achiasmatic sheep dogs. ${ }^{19}$

The major query that repeatedly arises when considering either of the two major optic pathway misrouting conditions, is how the brain and sensory systems develop, adapt to and function under such remarkable 'miswired' conditions. ${ }^{20-22}$ How the visual system functions and adapts to erroneous and conflicting visual input has proved of considerable research and clinical interest not only for studies concerning visual pathway development but also for gaining a better understanding of the relationship between misrouted optic pathways and the typically concomitant ocular motor misalignments and/or instabilities. ${ }^{1,2,16-18,20-27}$ From the latter disarrangements, the relevant issue of binocularity also emerges. ${ }^{10,16-18,20-23}$

A central issue of the present overview is whether the albino or achiasmatic visual system can adapt to the aberrant retinal-fugal projections, subsequent visuotopic mirror reversals and resultant ocular motor irregularities sufficiently to allow a substrate for binocular function. The first step in addressing this query is practical and simply concerns the methodology involved in the non-invasive detection of misrouted projections. The brief description of misrouting detection procedures is followed by ocular motor studies and the results of binocular tests of global stereopsis in albinos and achiasmatics. 


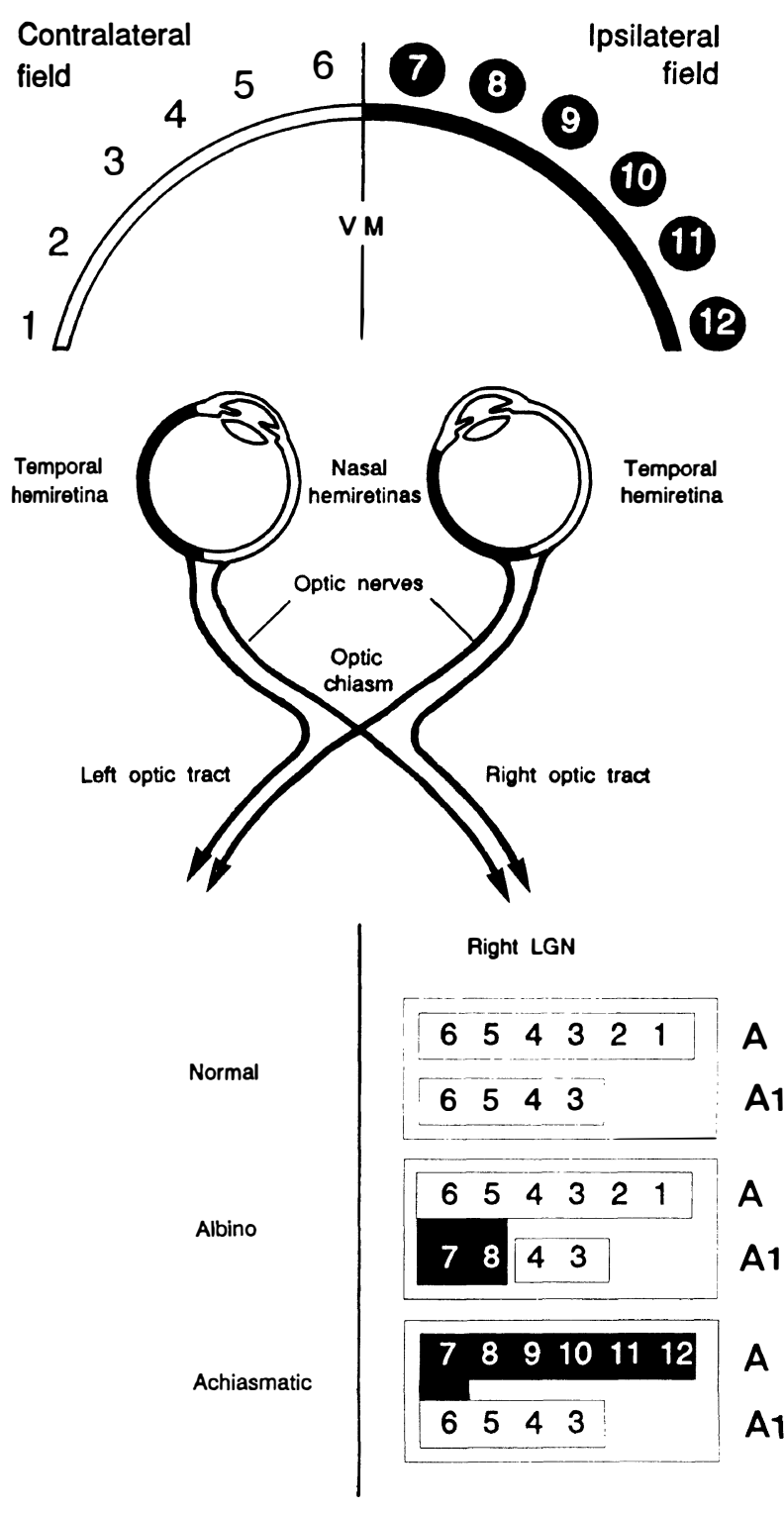

Fig. 1. Schematic of the visual field representation onto two adjacent right dorsal lateral geniculate nucleus ( $L G N)$ layers. Normally contralateral hemi-visual field representations in laminae $A$ and $A 1$ are in register; nasal retinal projections from the contralateral, left eye project to $L G N$ layer A; temporal retinal projections from the ipsilateral, right eye project to $L G N$ layer $A 1$. For the albino, the medial portion of layer $A 1$ representing a portion of the ipsilateral visual field is misprojected and misaligned with the corresponding projections of layer $A$. For the achiasmatic, the entire ipsilateral hemifield projected onto the nasal retina of the right eye is erroneously represented in right $L G N$ layer $A$; temporal retinal projections from the same eye project to ipsilateral, right LGN layer $A 1$. For both the albino and the achiasmatic, although retinalfugal fibres misproject to the wrong side of the brain, termination is at the correct LGN locus for retinal area. Concurrently visual field representation is presented in partial or complete mirror reversal, respectively. (From Apkarian et al. $^{2}$; adapted from Williams et al. ${ }^{3}$ and Guillery et al. ${ }^{20}$ )

\section{NON-INVASIVE DETECTION OF CHIASMAL CROSSING DEFECTS}

In humans, the misrouting of retinal cortical projections can be readily recorded from the surface of the scalp in the form of interocular hemispheric response lateralisation of the visual evoked potential (VEP) following full-field monocular stimulation. ${ }^{28-30}$ Because of the striking individual differences in cortical neuroanatomy, ${ }^{31-33}$ VEP hemispheric asymmetry per se is not a reliable index of misrouting. Of importance, are full-field interocular comparisons following appropriate VEP stimulation. To stress this point, in Fig. 2, binocular and monocular VEP amplitude at a given response latency is plotted as a function of electrode from left to right occiput for four normal and four albino controls. ${ }^{29}$ These subjects were selected as they each presented with interocular amplitude differences and also were representative of the remarkable variability in response lateralisation across subjects. For each function, a lateralisation value is ascribed which defines where across the electrode array the potential distribution shows its greatest activity. Once a lateralisation value per eye is obtained, an interocular asymmetry index is derived by subtracting the lateralisation value of the right eye from that of the left. The rectangular bars indicate the calculated asymmetry index of each data set. Based on laboratory norms, asymmetry index values greater than \pm 0.7 are significant. ${ }^{29,30}$ As clearly depicted, significant interocular contralateral asymmetry indices are present only for the albinos. Moreover, the contralateral hemispheric shift in the potential distribution from left to right eye stimulation, constituting the classic albino VEP signature, is both specific and pathognomonic for the albino condition.

Thus, with an appropriate VEP test protocol which is also age-dependent, the contralateral VEP asymmetry profile can be recorded in albinos regardless of genotype or phenotype, as depicted in Figs. 3 and 4. In Fig. 3,VEP asymmetry is present for the pattern onset responses from an adult genotyped as an oculocutaneous autosomal recessive albino as well as from an adult genotyped as X-linked ocular albino. Fig. 4 further emphasises the decisiveness of the VEP albino asymmetry paradigm in differential diagnosis. In this example, the monocular VEPs from an albino with the atypical absence of ocular motor instability readily show interocular contralateral asymmetry, whereas the monocular VEPs from a non-albino individual with idiopathic congenital nystagmus do not.

The high sensitivity and selectivity of the VEP albino misrouting test has proved clinically viable for albino detection and differential diagnosis, particularly in infants and young children. ${ }^{29}$ The VEP albino 

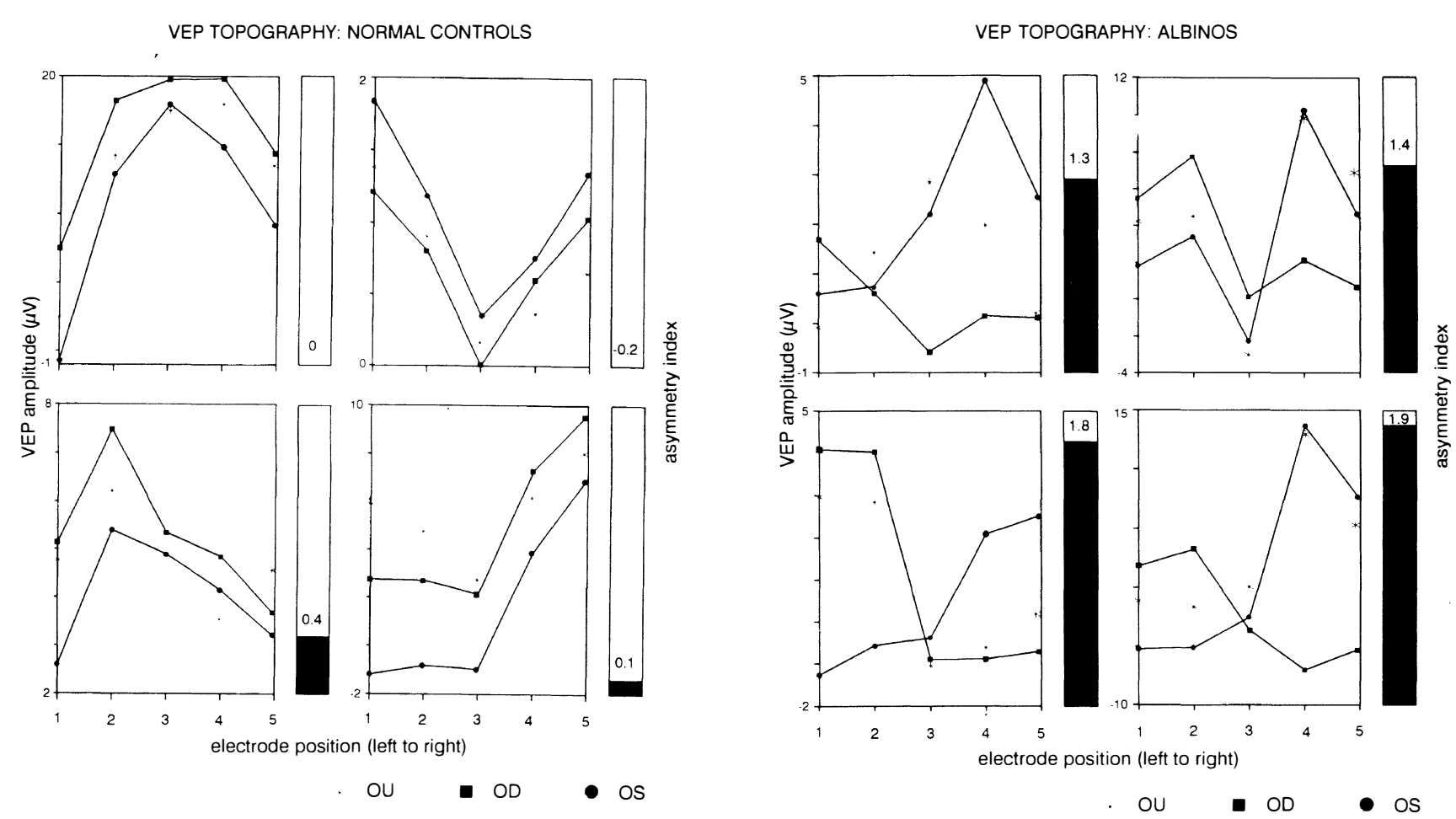

Fig. 2. Intersubject variability in VEP hemispheric response lateralisation for four normal controls (left) and four albinos (right). Binocular $(O U$, starred symbols), right eye (OD, filled squares) and left eye (OS, filled circles) VEP amplitude (peak to baseline) of the $C_{1}$ component of the pattern onset (40 ms on/460 ms off) response is plotted as a function of electrode derivation from left to right occiput. Interocular, hemispheric asymmetry index values for each monocular data set are also presented. Maximum contralateral asymmetry in which the response peaks across the left occiput with right eye stimulation and across the right occiput with left eye stimulation is denoted by an index value of 2. Maximum ipsilateral asymmetry in which right hemispheric lateralisation is recorded with right eye stimulation and vice versa is denoted by the value -2 (not shown). Equal left and right eye hemispheric response lateralisation is denoted by the value of 0 . Statistically significant interocular asymmetry is considered for index values greater than \pm 0.7 . Significant contralateral asymmetry indices are present only for the albinos regardless of the striking individual differences in hemispheric response lateralisation. (Adapted from Apkarian. ${ }^{29}$ )

misrouting test has also played a major role in the discovery of newly identified non-decussating retinal-fugal fibre syndrome. ${ }^{1,2}$ Fig. 5 depicts the VEP profile of an achiasmatic (AC1) who was initially referred for VEP testing for differential diagnosis. Because this patient presented with congenital nystagmus the clinical question during referral was whether the child had albinism or idiopathic congenital nystagmus. In Fig. 5 the VEP response profile of this child is compared with the responses from an age-matched normal control. The monocular VEP responses of the achiasmatic child demonstrate clear evidence of misrouting, but rather than the interocular contralateral asymmetry pathognomonic to albinism, interocular ipsilateral asymmetry is recorded. That is, following full-field monocular stimulation, the peak of the potential distribution localises to the ipsilateral occiput. The responses in Fig. 5 clearly show that the VEP misrouting correlate for the achiasmatic condition is the attenuation of primary visual evoked responses from the occiput contralateral to the eye of stimulation. In general, the VEP profile for the various optic pathway conditions and configurations discussed can be readily sum- marised by: (1) ipsilateral interocular asymmetry in achiasmatic syndrome, (2) contralateral interocular asymmetry in albinism and (3) interocular symmetry in normal controls and in idiopathic or hereditary congenital nystagmus.

In addition to the abnormal VEP response lateralisation in the achiasmatic condition, it is important to appreciate that non-decussating retinal-fugal fibre syndrome is an isolated split chiasm condition. That is, there are no identifiable, associated growth disturbances, midline anomalies, lesions, tumours or the like that typically accompany or produce an abnormal chiasmatic condition. ${ }^{34-37}$ The isolated achiasmatic condition is confirmed by magnetic resonance imaging (MRI) in which the optic chiasm is emphasised as depicted in Fig. 6. The T1-weighted axial scan clearly shows the complete failure of the two intracranial optic nerves to approach the midline, requiring retinal-fugal fibres to continue an ipsilateral retinal-cortical path. The optic structures are constrained to maintain uncrossed trajectories as they pass unobstructed onto the thalamic structures.

In patients with non-decussating retinal-fugal fibre 


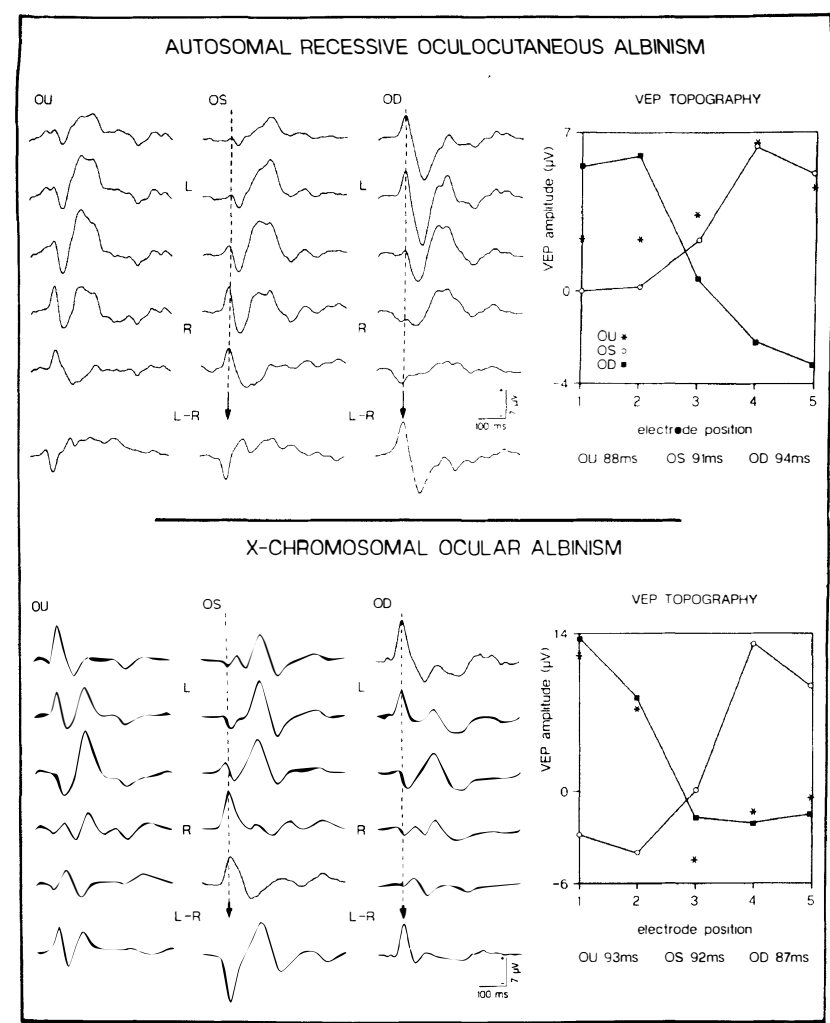

Fig. 3. Binocular $(O U)$, left eye (OS) and right eye (OD) pattern onset $(40 / 460 \mathrm{~ms})$ responses from two different albino genotypes: autosomal recessive oculocutaneous albinism and $X$-linked ocular albinism. In this and comparable VEP profiles, the upper five traces from each column represent responses derived from one of five electrodes positioned across the occiput from left ( $L$, upper traces) to right ( $R$, lower traces). The bottom traces of each column represent a difference potential in which trace 4 from the right occiput $(R)$ is subtracted from trace 2 from the left occiput $(L)$. The vertical dashed lines indicate the $C_{I}$ response latency at which VEP is measured and plotted as a function of electrode as depicted in the VEP amplitude versus electrode plots. A contralateral hemispheric shift in the potential distribution from left to right eye stimulation constitutes the classic albino VEP signature. The stimulus conditions included a computer generated checkerboard pattern (55'), mean luminance $90 \mathrm{~cd} / \mathrm{m}^{2}$, field size $10^{\circ}$. In this example, contralateral asymmetry for both albino genotypes is reflected in the potential distributions, in the polarity reversal of the difference potentials and in the crossover of the monocular amplitude versus electrode functions. (From Apkarian. ${ }^{73}$ )

syndrome, despite the striking achiasmatic condition, ophthalmic evaluation confirms normal visual fields. On the basis of trauma-induced split-chiasm cases $^{38-40}$ or experimental optic chiasm transection studies, ${ }^{41,42}$ one might have expected nasal retinal scotomata and corresponding bi-temporal hemianopsia, but this is certainly not the case in patients with inborn, non-decussating retinal-fugal fibre syndrome. Regarding visual fields in chiasmal crossing defects in general, it is of interest to note that human albinos also do not show visual field losses related to the paucity of ipsilateral temporal retinal projections, i.e. bi-nasal hemianopsia. Interestingly, however, in

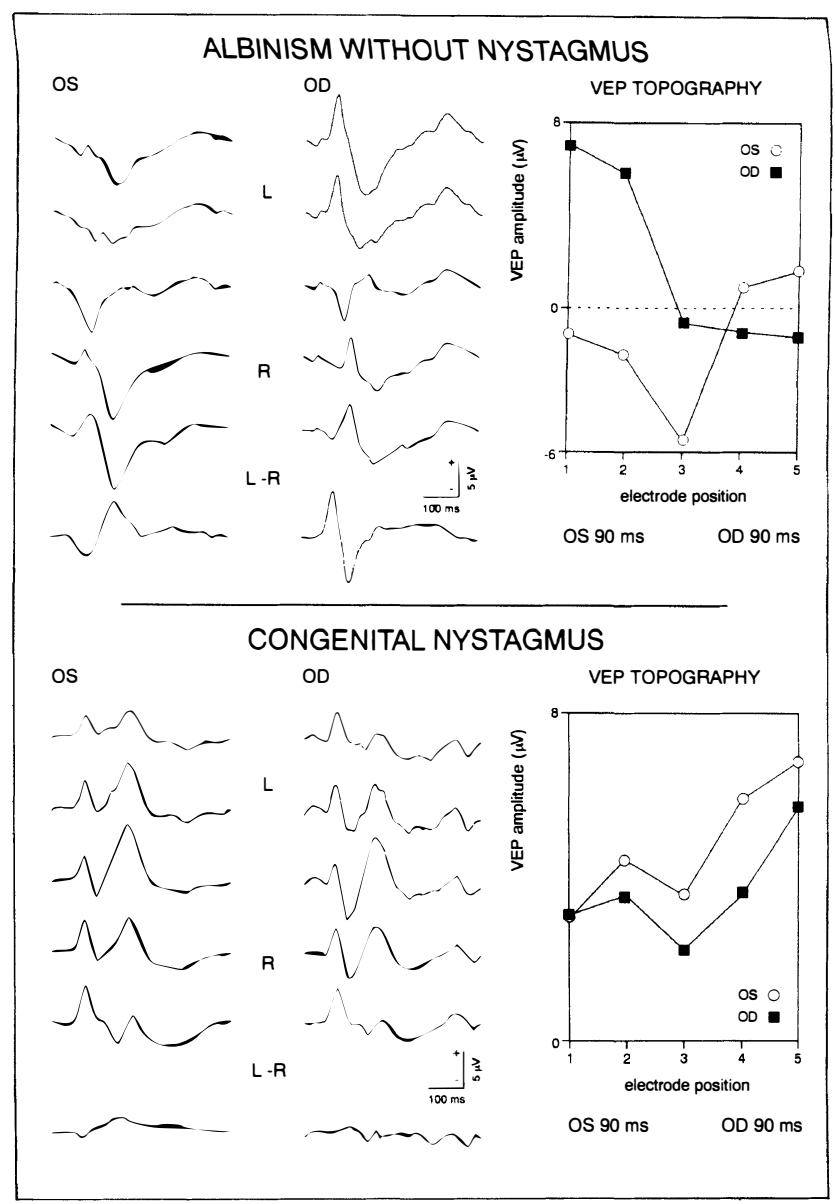

Fig. 4. Left eye (OS) and right eye (OD) pattern onset (40/ $460 \mathrm{~ms}$ ) responses of an albino with no nystagmus and a non-albino with idiopathic congenital nystagmus. The latency at which VEP amplitude of the pattern onset $C_{1}$ component was measured and plotted as a function of electrode position is denoted. The albino VEP profile shows a general left hemispheric response dominance and also greater amplitude responses for OD than $O S$. In contrast, the patient with congenital nystagmus shows a right hemispheric response dominance and greater amplitude responses for $O S$ than $O D$. Despite the general hemispheric response dominance and the interocular amplitude differences, interocular contralateral asymmetry following full field monocular stimulation is present only for the albino. Note also for the albino, the change in the potential distributions from left to right eye stimulation, the polarity reversal of the difference potentials and the crossover in the VEP topography plot. (From Apkarian. ${ }^{73}$ )

some albino-related species, particularly the so-called Midwestern Siamese cat, nasal visual field losses have been documented. ${ }^{20,43,44}$ Concurrent with normal visual fields, clinical features in the achiasmatic condition relevant to the present discussion include ocular motor instability as characterised in more detail below, interocular misalignments, and torticollis. Additional relevant clinical features of two unrelated, naturally occurring achiasmatics as well as a group of albinos whose binocularity results are discussed in the present study are listed in Table I. Note from the age range indices that the achiasmatics were evaluated over a period of several years. 
OS
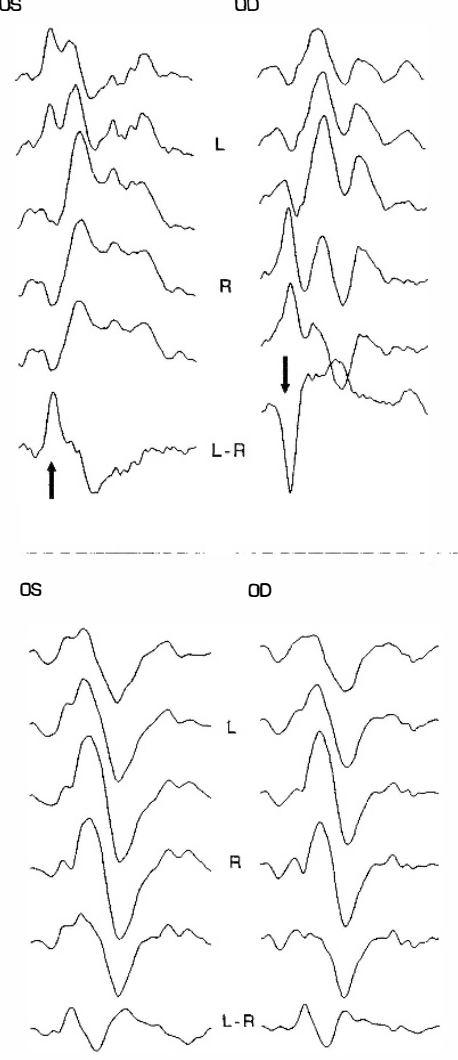

$\mathrm{QD}$
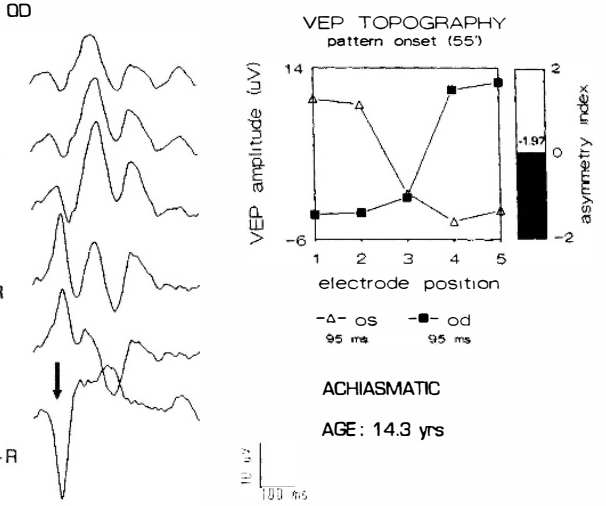

ACHIASMATIC

AGE : 14.3 yrs<smiles>C1=CC2CCC=C1C2</smiles>

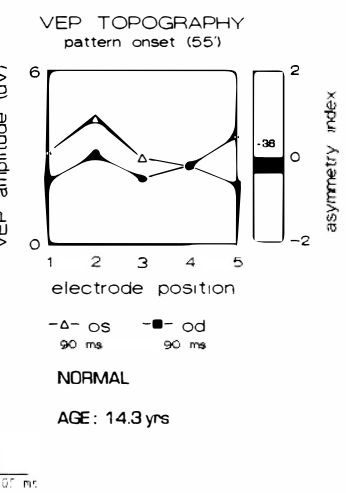

Fig. 5. Monocular pattern onset responses for achiasmatic patient AC1 tested at about 14 years of age compared with an age-matched normal control. For stimulus, recording and data analysis details, see Figs. 2-4. For the achiasmatic, following left eye (OS) stimulation, a major positive peak of the pattern onset response lateralises to the left hemisphere; with right eye $(O D)$ stimulation, the response lateralises to the right. The ipsilateral asymmetry is reflected in the potential distributions, the polarity reversal of the difference potentials and the striking VEP amplitude versus electrode position functions. Note also the highly significant asymmetry index $(-1.97)$ of the achiasmatic compared with that (-0.36) of the normal age-matched control. (From Apkarian.')

\section{BINOCULARITY AND CHIASMAL CROSSING DEFECTS}

Having thus described the presence and VEP detection of the two major forms of naturally occurring chiasmal defects, the next issue to be addressed concerns binocularity and whether or not misrouting conditions per se preclude binocular function, in general, and stereo vision, in particular. Previous albino studies across several species suggest that the answer to this query is negative. ${ }^{10,20,24}$ As discussed in the introduction and also by Guillery in an accompanying study, ${ }^{45}$ aberrant decussation patterns preclude normal visuotopic and retinotopic mapping throughout the visual pathways. One consequence of the abnormal visual pathway projections and disrupted functional organisation is a paucity or absence of normal binocular substrates for the encoding of retinal disparity and thus depth

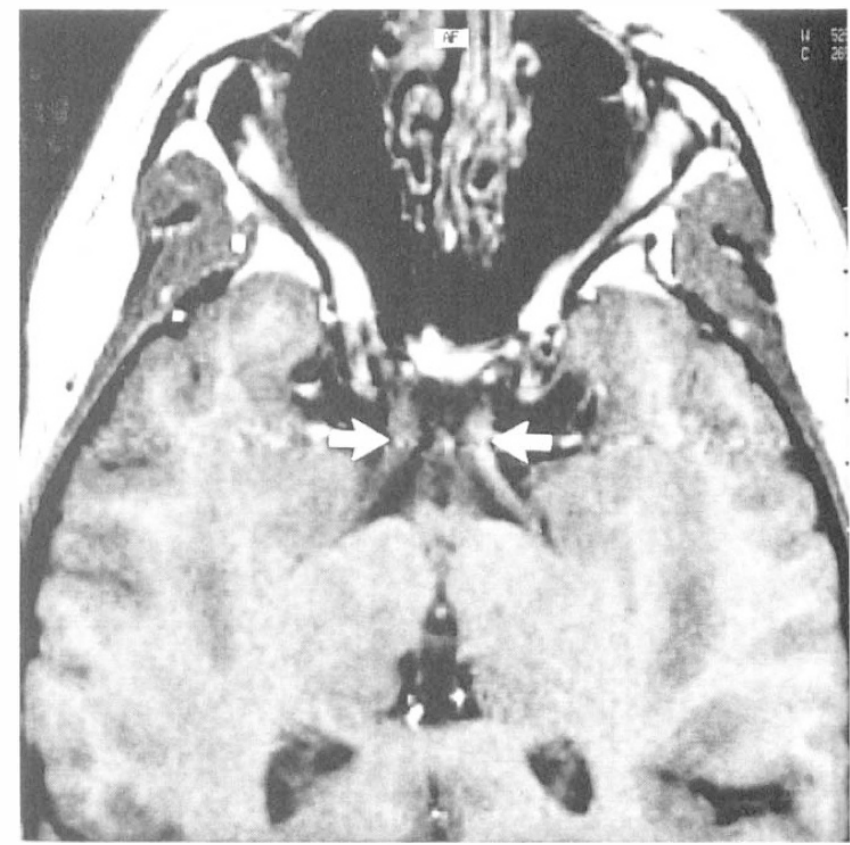

Fig. 6. The T1-weighted MRI section representing a transverse axial scan through the optic nerves and tracts shows continuity between the two without the expected chiasmal plate. Clearly illustrated from top to bottom are the optic nerves, the region of the missing chiasm, and the suprasellar cistern. The arrows, superimposed upon highcontrast blood flow artefacts of the internal carotid arteries, indicate the expected location of the missing chiasm. (Adapted from Apkarian et al. ${ }^{2}$ )

information. Whether the visual system, with chiasmal crossing defects and accompanying aberrant mapping and organisation, can support binocularity either directly via retino-cortical projections or indirectly via, for example, cortico-cortical or

Table I. Clinic status

\begin{tabular}{|c|c|c|c|c|c|c|c|c|c|}
\hline $\begin{array}{l}\text { Case } \\
\text { No. }\end{array}$ & $\begin{array}{l}\text { Age } \\
\text { (Yns) }\end{array}$ & $\begin{array}{l}\text { Clinic } \\
\text { Diag }\end{array}$ & $\begin{array}{l}\text { VEP } \\
\text { Asym }\end{array}$ & $\begin{array}{l}\text { Visual } \\
\text { Acuity }\end{array}$ & $\begin{array}{l}\text { Fundus } \\
\text { Pigment }\end{array}$ & $\begin{array}{l}\text { Fovea } \\
\text { Reflex }\end{array}$ & $\begin{array}{l}\text { Iris } \\
\text { Dia }\end{array}$ & Nystag & $\underset{\text { Alignment }}{\text { Ocular }}$ \\
\hline $\mathrm{ACl}$ & $9 \cdot 16$ & $\mathrm{ACH}$ & ipsil & .3 .2 & $\bullet$ & $\bullet$ & 0 & $\bullet$ & esotropia alt \\
\hline $\mathrm{AC} 2$ & $4-10$ & $\mathrm{ACH}$ & ipsil & .2 .2 & $\bullet$ & - & O & $\bullet$ & esotropia alt \\
\hline ALBI & 40 & OCA & contra & $.5 \ldots 5$ & $\bullet$ & O & $\bullet$ & O & orthophoria \\
\hline ALB2 & 36 & OCA & contra & .5 .5 & $\bullet$ & c & $\bullet$ & $\bullet$ & exophoria \\
\hline ALB3 & 37 & OCA & contra & $.5 . .5$ & $\bullet$ & o & $\bullet$ & 0 & esuphuria \\
\hline ALB4 & 9 & OCA & contra & $.4 . .4$ & $\bullet$ & O & $\bullet$ & 0 & orthophoria \\
\hline ALB5 & 22 & $\mathrm{OA}$ & contra & $.5 . .5$ & • & O & $\bullet$ & $\bullet$ & orthophoria \\
\hline ALB6 & 24 & OCA & intra & $.2 \ldots 2$ & $\bullet$ & O & $\bullet$ & $\bullet$ & esuphoria \\
\hline ALB7 & 72 & OCA & contra & $.3 . .2$ & $\bullet$ & o & $\bullet$ & $\bullet$ & exophoria \\
\hline ALB8 & 29 & OCA & $\star$ & $.3 . .3$ & $\bullet$ & o & $\bullet$ & O & orthophoria \\
\hline ALB9 & 22 & OCA & contra & .5 .5 & $\bullet$ & 0 & $\bullet$ & O & orthophoria \\
\hline ALB 10 & 20 & OCA & contra & $.2 \ldots 3$ & $\bullet$ & 0 & $\bullet$ & $\bullet$ & orthophoria \\
\hline ALBII & 17 & $\mathrm{OA}$ & contra & $.2 \ldots 2$ & $\bullet$ & O & $\bullet$ & $\bullet$ & exotropia al \\
\hline ALBI2 & 35 & OCA & contra & $.4 \ldots 3$ & ○ & o & $\bullet$ & $\bullet$ & exstropia al \\
\hline ALB 13 & 26 & OCA & contra & $.3, .3$ & ○ & O & $\bullet$ & $\bullet$ & orthophoria \\
\hline ALBI4 & 18 & OCA & contra & $.3 . .2$ & ○ & o & $\bullet$ & $\bullet$ & orthophoria \\
\hline ALB15 & 29 & $\mathrm{OA}$ & contra & .1 .1 & $\bullet$ & 0 & $\bullet$ & $\bullet$ & esotropia \\
\hline ALBI6 & 35 & OCA & contra & $.2, .3$ & $\bullet$ & O & $\bullet$ & $\bullet$ & exotropia \\
\hline ALBI7 & 22 & OCA & contra & $.1 . .1$ & O & 0 & $\bullet$ & $\bullet$ & esotropia alt \\
\hline ALB18 & 34 & OCA & contra & $.3 . .3$ & $\bullet$ & 0 & $\bullet$ & $\bullet$ & esotropia \\
\hline Key: & & $\bullet$ & prisent & & 0 & absent & & $\star$ & unable to test \\
\hline
\end{tabular}


Table II. Summary of stereo results

\begin{tabular}{|c|c|c|c|c|c|}
\hline $\begin{array}{c}\text { Case } \\
\text { No. }\end{array}$ & Titmus & TNO & $\begin{array}{l}\text { Static } \\
\text { RDS }\end{array}$ & $\begin{array}{l}\text { Vertical } \\
\text { Pursuit }\end{array}$ & $\begin{array}{c}\text { Dynamic } \\
\text { RDS }\end{array}$ \\
\hline AC1 & $\square$ & $\square$ & $\square$ & 口 & 0 \\
\hline $\mathrm{AC} 2$ & $\square$ & $\square$ & $\square$ & 口 & O \\
\hline ALB 1 & ש & $\square$ & $\star$ & $\star$ & $\star$ \\
\hline ALB2 & 口 & $\square$ & $\star$ & $\star$ & $\star$ \\
\hline ALB3 & 口 & 口 & $\star$ & $\star$ & $\star$ \\
\hline ALB4 & 口 & 口 & $\star$ & $\star$ & $\star$ \\
\hline ALB5 & $\square$ & $\square$ & 口 & 口 & 口 \\
\hline ALB6 & 口 & $\square$ & $\mathbf{\square}$ & $\mathbf{\square}$ & 口 \\
\hline ALB7 & ש & $\square$ & $\mathbf{\square}$ & $\mathbf{\square}$ & $\mathbf{\square}$ \\
\hline ALB8 & 口 & 口 & 口 & 口 & 口 \\
\hline ALB9 & 口 & $\mathbf{\square}$ & 口 & 口 & 口 \\
\hline ALB10 & $\square$ & $\square$ & $\square$ & $\star$ & $\star$ \\
\hline ALB11 & $\square$ & $\square$ & $\square$ & $\star$ & $\star$ \\
\hline ALB12 & $\square$ & $\square$ & $\square$ & $\mathbf{\square}$ & $\square$ \\
\hline ALB13 & $\square$ & $\square$ & $\square$ & 口 & $\square$ \\
\hline ALB14 & $\square$ & $\square$ & $\square$ & 口 & $\square$ \\
\hline ALB15 & $\square$ & $\square$ & $\square$ & $\mathbf{\square}$ & $\square$ \\
\hline ALB16 & $\square$ & $\square$ & $\square$ & 口 & $\square$ \\
\hline ALB17 & $\square$ & $\square$ & $\square$ & 口 & $\square$ \\
\hline ALB18 & $\square$ & $\square$ & $\square$ & $\mathbf{\square}$ & $\square$ \\
\hline Key: $\square$ & positive & $\square=$ & negative & $\star=$ & no data \\
\hline
\end{tabular}

cortical-thalamic projections, is readdressed in the present overview by reviewing the results of a previously reported study of albino binocular function. $^{46}$

During a period several years ago, in which optimum VEP test parameters were being determined for the non-invasive detection of misrouting, ${ }^{28}$ the albinos tested underwent not only comprehensive genetic evaluation but also extensive ophthalmic evaluation. One unexpected result from the extensive screening procedures was that some albinos were shown to demonstrate not only binocular fusion but indeed also stereopsis, more specifically coarse, global stereopsis as evinced by standard clinical test plates including the Titmus polarised vectograph stereo test (Titmus Optical Co., Petersburg, VA) and the TNO anaglyph random-dot stereo test (Laméris Instruments, Utrecht, Netherlands). It is of importance to note that those relatively few albinos who demonstrated stereo vision, also presented with normal ocular alignment with the exception of various phorias. A summary of the VEP findings and the ophthalmic evaluation including interocular alignment for 9 albinos (ALB1 to ALB9) testing positive for stereopsis and 9 albinos (ALB10 to ALB18) testing negative is presented in Table II together with the achiasmatic data. As outlined in Table II, some of the albinos evincing stereo vision had nystagmus; some did not. In evaluating the patients' performance with the standard clinic test plates, procedures as outlined by the manufacturers were carefully followed. In addition, if a positive response was obtained, the test plate was turned upside down and the patient was requested to respond to the direction of the depth percept. For the test plates in general, pass/fail criteria were employed; resultant albino stereo acuity estimates showed high intersubject and intrasubject variability. For the Titmus test, intersubject albino stereo acuity ranged from $80 \mathrm{~s}$ to coarser; for the TNO test stereo acuity ranged from $60 \mathrm{~s}$. In general, minimum albino stereo acuity values were below normal and can be

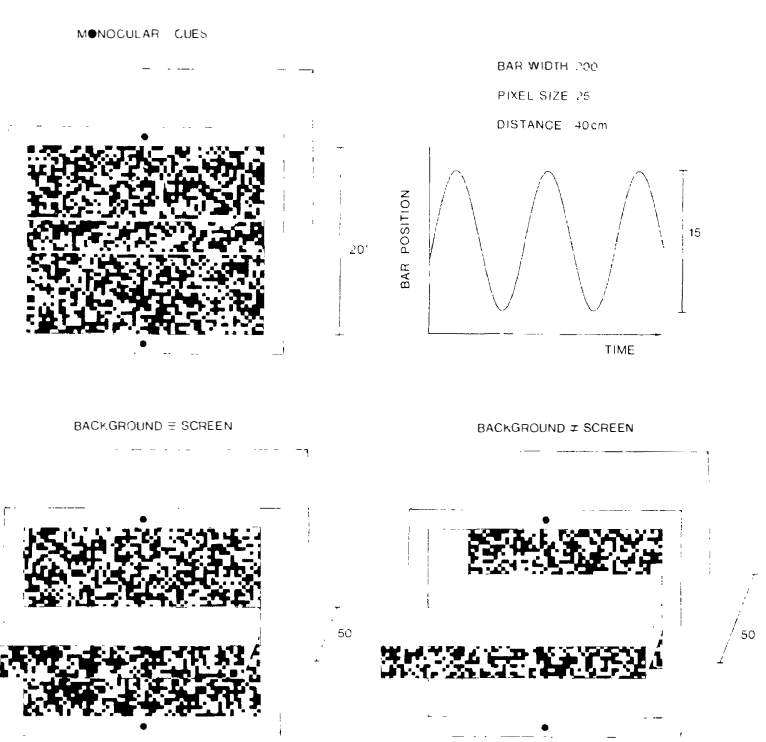

Fig. 7. Schematic representation of computer-generated stereograms presented onto two monochromatic monitors and viewed fused (as depicted) through a haploscopic configuration. Fusion was assured by alignment of two LEDs appearing at the top and bottom of the screen surround. The horizontal stimulus bar moved sinusoidally, up and down the screen at varying rates (upper, right). The stimulus bar generated by a zero shift in pixels was viewed with monocular cues (upper, left). The stimulus bar with a given pixel shift appeared displaced from the background to yield a target visible only in stereo (lower, left). Lastly, with both bar and background presented in opposite disparity, the stereo target and the background were viewed in crossed and uncrossed disparity (or vice versa) respectively (lower, right). (From Apkarian and Reits. ${ }^{46}$ ) 
considered primarily to reflect the ability for coarse, global stereopsis. A pass/fail summary of the test plate results for all the patients is listed in Table II under columns 'Titmus' and 'TNO'.

Because stereo test figures, even TNO figures, can be recognised in the absence of true stereopsis, ${ }^{47}$ albino binocularity was also evaluated with TVgenerated random-dot stereograms as sketched in Fig. 7 and as described in more detail by Apkarian and Reits. ${ }^{46}$ The stereo target was displaced either in front or behind the screen in crossed or uncrossed disparity $(50 \mathrm{~min})$. In addition, to preclude positive response bias based on binocular correlation without stereo, the target background was also presented in crossed or uncrossed disparity. In this latter condition, when the stereo bar was presented in crossed disparity (25 min, in front of the screen), the surround was presented in uncrossed disparity ( 25 min, behind the screen) or vice versa. In one test protocol, the stereo target, a horizontal bar (subtending approximately $3.5^{\circ}$ by $25^{\circ}$ ) was positioned at the top, middle or bottom of the test screen. The patient was asked to state the position of the bar and the direction of depth, if present. The results of this test are presented in Table II under the column heading of static random-dot stereogram ('static RDS').

To test for stereo vision more objectively, advantage was taken of the albino ability to track objects readily and accurately in the vertical plane. ${ }^{25}$ Previous investigations have clearly confirmed the usefulness of objectively assessing stereopsis with an

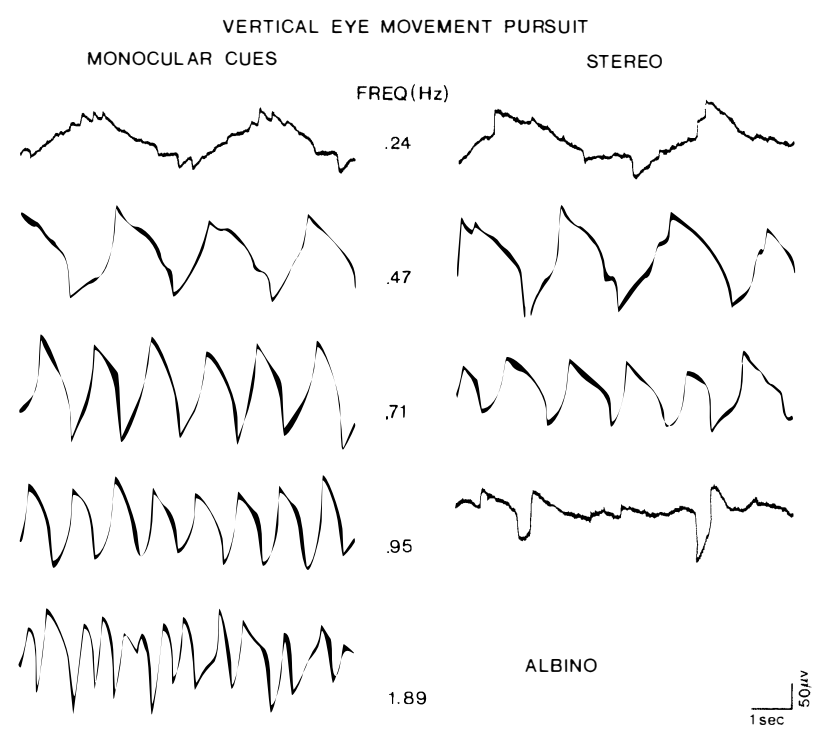

Fig. 8. Vertical eye movements of albino ALB8 during dichoptic viewing of the stimulus bar with monocular cues (left) and in stereo (right). The stimulus bar moved vertically across the screen at varying rates. Note that for lower temporal frequencies the ocular motor following profiles with monocular cues or in stereo are comparable. With higher rates, stereo pursuit diminishes. (From Apkarian and Reits. ${ }^{46}$ ) ocular motor paradigm, such as stereo-induced optokinetic nystagmus. ${ }^{48,49}$ Since the capacity for vertical smooth pursuit typically is present in all albinos regardless of the accompanying horizontal ocular motor instabilities ${ }^{25}$ albino stereo vision also was evaluated by having patients track the horizontal target bar as it drifted upward or downward across the monitor screen. The drift profile was sinusoidal at rates that varied from $0.24 \mathrm{~Hz}$ to $2.37 \mathrm{~Hz}$. The drifting bar was presented with monocular cues, in crossed disparity or in uncrossed disparity. In the study under discussion, albino vertical eye movements were recorded (coarsely) by electro-oculography (EOG) methodology. That patients could readily perform the tracking task with monocular cues is summarized in Table II under the column heading of 'vertical pursuit'. EOG traces of vertical pursuit at varying target velocities with monocular cues is presented for ALB8 in the leftmost column of Fig. 8. EOG traces in the rightmost column for ALB8 are in response to the drifting target presented in stereo with crossed disparity. Although vertical pursuit of the stereo targets is more degraded than pursuit with monocular cues for higher stimulus rates, tracking of the stereo target at lower rates is clearly present. Note from Table I that ALB8 also presented with no nystagmus. However, some albinos with nystagmus also could demonstrate stereo as shown for ALB7, in Fig. 9. In Fig. 9, stereo contours were presented at a low target rate $(0.47 \mathrm{~Hz})$ in either crossed or uncrossed disparity; albino EOG responses depicted at the right for ALB7 are compared with those at the left for a normal control. In general, the albinos, with or without nystagmus, who demonstrated stereo vision on at least one of the three static stereo tests and for whom the ocular motor tracking task was
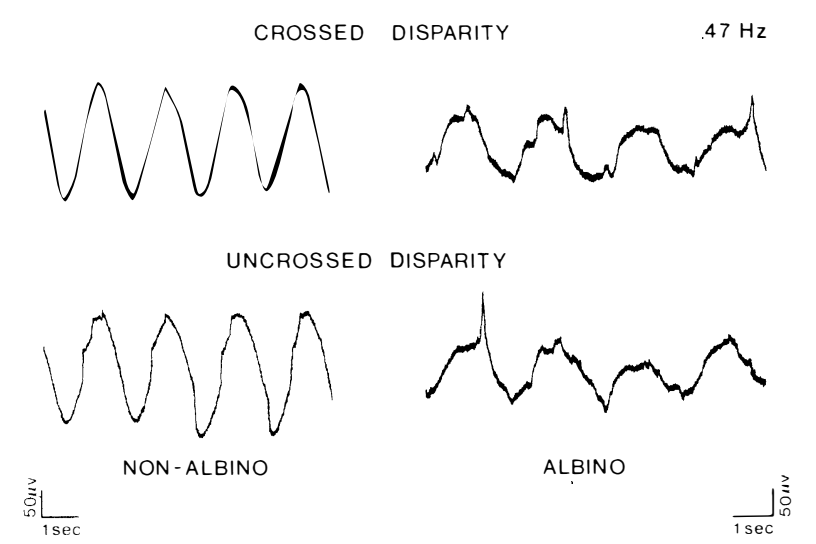

Fig. 9. Vertical pursuit with the stimulus bar displaced in front of the display in crossed disparity and moving against a background the image of which was projected in uncrossed disparity (upper traces) or vice versa (lower traces). Although the albino responses ( $A L B 7)$ show more EOG noise artefacts than those of the normal control, both the normal and albino profiles show clear vertical pursuit to targets presented in either crossed and or uncrossed disparity. (From Apkarian and Reits. ${ }^{46}$ ) 
implemented, typically showed appropriate vertical pursuit to stereo targets, at least for the lower target velocities, regardless of whether the targets were presented in crossed or uncrossed disparity.

The positive stereo results are in strong support of the capacity for stereo vision, that is, global or coarse stereo vision, in at least some albinos. These unanticipated findings certainly give rise to the question of which visual pathways actually mediate binocularity in albinos. While stereopsis in albinos may be supported by residual appropriately projecting temporal retinal-fugal fibres, previous electrophysiological and behavioural studies concerning albino animal models, ${ }^{10,18,50-54}$ vertical meridian overlap ${ }^{39,55}$ and corpus callosum and/or optic chiasm transection $^{56-62}$ suggest that a more likely candidate in providing an adequate neural substrate for albino binocularity involves inter- and intracortical communication via corpus callosal connections. The developmental course of the corpus callosum with accompanying aberrant retinal geniculate projections has been shown to compensate for the albino-like misrouting by dramatic reorganisation of callosal connections. ${ }^{63,64}$ The presence of global stereopsis in some albinos suggests that callosal connections have been reshaped and redistributed during early visual pathway development. This early reorganisation and remarkable plasticity appears to accommodate the processing of binocularly disparate information, thus providing an anatomical functional substrate that supports, in chiasmal crossing defects, at least coarse or global stereopsis.

While animal models and trauma-induced split chiasm conditions, as cited above, readily support theories of corpus callosum mediated stereopsis, naturally occurring, isolated, non-decussating retinal-fugal fibre syndrome also presents itself as a most remarkable test model of these hypotheses. For example, previous studies document that stereo vision, albeit with field restrictions, was definitely present in a patient with isolated split chiasm due to trauma. ${ }^{57}$ Of considerable interest in this regard is that the naturally occurring achiasmatic patients described herein show, as described above, no visual field losses, implying that plasticity of inter- and intracortical connections may be even more dramatic than in conditions of late onset trauma or surgically induced achiasmatic conditions. Contrary to expectations, however, the suggestion of plasticity also in binocularity does not come to fruition as neither of the naturally occurring achiasmatic children described herein show any evidence of stereo function.

The absence of stereopsis or, for that matter, even a functional substrate to support binocular fusion in non-decussating retinal-fugal fibre syndrome is verified by closer examination of the interocular

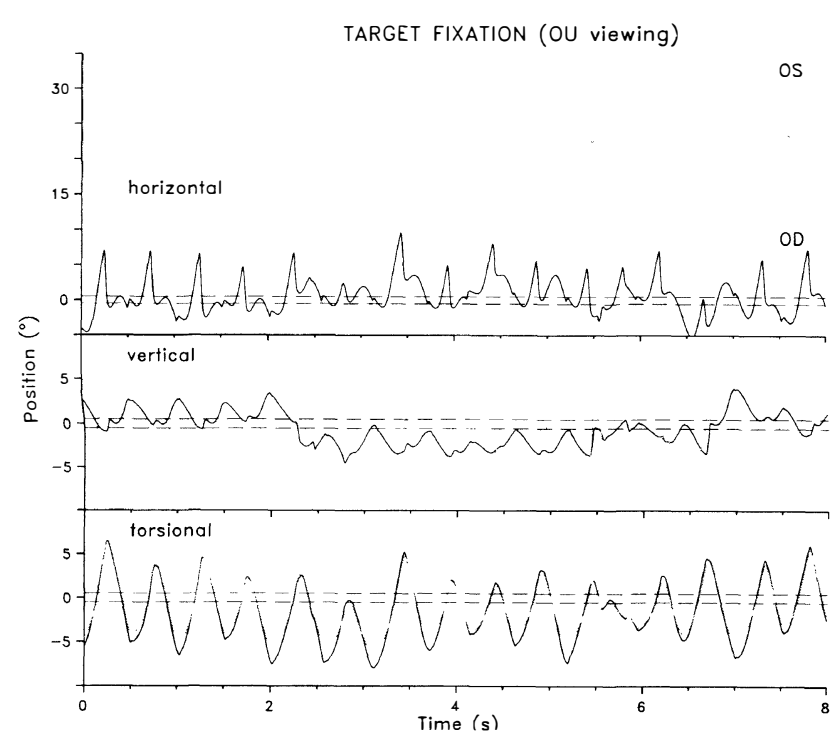

Fig. 10. Horizontal (upper traces), vertical (middle traces) and torsional (lower traces) eye movements in achiasmatic AC1 recorded with a dual-search coil technique. Calibrated eye position is plotted as a function of time. Dotted lines represent left eye position (OS), continuous, darker lines right eye position (OD). The horizontal dashed lines represent a pre-defined foveation window of $\pm 0.5^{\circ}$. Positive values along the ordinate indicate rightward or upward position or rotation to the right shoulder; negative values indicate leftward or downward position or rotation to the left shoulder. The ocular motor task included first fixating, binocularly, a target positioned at primary position $\left(0^{\circ}\right)$. The fixation paradigm then included a switch in fixation to a target displaced about $5^{\circ}$, down. Task completion was accomplished by returning fixation to primary position. Classic congenital nystagmus is recorded in the horizontal planes together with see-saw nystagmus in the vertical and torsional planes. Note for the congenital nystagmus traces, that interocular conjugacy is recorded in both amplitude and direction. For the vertical and torsional planes, pendular-like nystagmus is recorded along with vertical interocular directional disconjugacy (an interocular vertical amplitude difference also is present). Regarding interocular alignment, interocular, horizontal position differences indicate that the right eye is fixating the target while the left eye is esotropic and variably hypotropic. (From Apkarian et al. ${ }^{65}$ )

misalignments and ocular motor instabilities associated with this condition. In fact, examination of the accompanying achiasmatic ocular motor misalignments and instabilities reveals that testing for stereo function or even binocular fusion in inborn achiasmatic patients can be considered a non-viable proposition. This argument is supported by ocular motor investigations in the achiasmatic mutant Belgium sheep $\operatorname{dogs}^{27}$ as well as in the achiasmatic children, the latter of which are yet to be published in article form. ${ }^{26,65}$ A preview of the achiasmatic ocular motor profile is presented in Fig. 10, which depicts highly accurate dual-search coil recordings of horizontal, vertical and torsional left and right eye position for the older of the two achiasmatic children, AC1. Quantification of the achiasmatic eye move- 
ments reveals classic congenital nystagmus in the horizontal planes including characteristic waveforms. As presented in Fig. 10, the horizontal waveforms can be classified, after Dell'Osso and Daroff, ${ }^{66}$ as typical jerk nystagmus with extended foveation and with the superimposition of slow wave jerks. The horizontal congenital nystagmus traces depicted also show interocular conjugacy in both direction and amplitude. Interocular horizontal position differences indicate that the right eye is fixating the target while the left eye is esotropic and variable hypotropic. Classic congenital nystagmus together with variable expression of the horizontal, interocular misalignments is characteristic of albino ocular motor instabilities as well. ${ }^{25}$ What is atypical and rather exceptional in the achiasmatic condition is that concomitant with the horizontal nystagmus there is also a pendular nystagmus in the vertical and torsional planes. The pendular nystagmus is dysconjugate in the vertical planes and conjugate in the torsional planes. This form of nystagmus has been termed see-saw nystagmus and is characterised by upward movement and intorsion of one eye with simultaneous downward movement and extorsion of the fellow eye. ${ }^{67}$

It is of interest to note that the see-saw form of ocular motor instability is extremely rare, is typically identified with midline lesions, malformations or the like and also is typically accompanied by bitemporal hemianopisia. ${ }^{67-70}$ There are, however, even rarer reports of a form of congenital see-saw nystagmus in which the patients are apparently otherwise normal and also have normal visual fields. ${ }^{71,72}$ It is of interest to ponder whether or not these latter patients represent, in fact, undetected cases of non-decussating retinal-fugal fibre syndrome. However, of direct relevance to the present overview is that given the remarkable ocular motor profile in non-decussating retinal-fugal fibre syndrome, including the alternating esotropia and vertical disconjugacies, it would be rather astonishing if inborn achiasmatics did demonstrate evidence of binocular integration and function.

\section{CONCLUSIONS}

This overview demonstrates a dissociation between primary visual pathway anomalies of retinal cortical misprojections and binocular function. Despite misrouted temporal retinal fibres, some albinos have the capacity to process binocularly disparate images as they demonstrate clear evidence of the capacity for binocular fusion and global stereopsis. These binocularity results in albinos are of particularly interest with regard to albino animal models, which indicate a paucity of binocularity-driven cortical neurons in primary visual areas. These studies also suggest that inter- and intracortical disparity processing via corpus callosal connections may well provide the primary neural substrate to support albino binocularity. Although the quest to observe binocularity in the achiasmatic condition has failed, perhaps this naturally occurring chiasmal crossing defect will none-the-less stimulate the development of provisional models of the anatomical and physiological substrates that underlie highly unusual types of unyoked, dysconjugate eye movements. As postulated by Dell'Osso and Williams, ${ }^{27}$ certainly binocularity imposes a tight ocular motor yoking that precludes significant interocular differences for either eye position or eye movement trajectories. The present overview attempts to gain a better understanding of the direct and indirect visual pathways in chiasmal crossing defects and their relationship to single binocular vision and ocular motor coupling. Indeed, inborn errors of retinal-fugal projections, as described herein, may well yield insights into visual pathway development and how it is that the brain adapts to and processes sensory events even when left and right eye visual fields are cortically projected in mirror reversed order, partially, as in albinism, or completely, as in non-decussating retinal-fugal fibre syndrome.

Key words: Albinism, Non-decussating retinal-fugal fibre syndrome, Optic chiasm, Stereopsis, Nystagmus, Visual pathway, Visual evoked potentials, Eye movements, Corpus callosum.

\section{REFERENCES}

1. Apkarian P, Bour L, Barth PG. A unique achiasmatic anomaly detected in non-albinos with misrouted retinal-fugal projections. Eur J Neurosci 1994;6:501-7.

2. Apkarian P, Bour LJ, Barth PG, Wenniger-Prick L, Verbeeten B Jr. Non-decussating retinal-fugal syndrome. An inborn achiasmatic malformation associated with visuotopic misrouting, visual evoked potential ipsilateral asymmetry and nystagmus. Brain 1995;118: 1195-216.

3. Williams RW, Hogan D, Garraghty PE. Target recognition and visual maps in the thalamus of achiasmatic dogs. Nature 1994;367:637-9.

4. Lund RD. Uncrossed visual pathways of hooded and albino rats. Science 1965;149:1506-7.

5. Giolli RA, Guthrie MD. The primary optic projections in the rabbit: an experimental degeneration study. $\mathrm{J}$ Comp Neurol 1969;136:99-126.

6. Creel DJ. Visual system anomaly associated with albinism in the cat. Nature 1971;231:465-6.

7. Guillery RW. An abnormal retinogeniculate projection in the albino ferret (Mustela furo). Brain Res 1971; 33:482-5.

8. Guillery RW, Kaas JH. A study of normal and congenitally abnormal retinogeniculate projections in cats. J Comp Neurol 1971;143:73-100.

9. Guillery RW, Sitthi Amorn C, Eighmy BB. Mutants with abnormal visual pathways: an explanation of anomalous geniculate laminae. Science 1971;174:831-2.

10. Kalil RE, Jhaveri SR, Richards W. Anomalous retinal pathways in the Siamese cat: an inadequate substrate for normal binocular vision. Science 1971;174:302-5.

11. Berman N, Cynader M. Comparison of receptive-field organization of the superior colliculus in Siamese and normal cats. J Physiol (Lond) 1972;224:363-89. 
12. Kaas JH, Harting JK, Guillery RW. Representation of the complete retina in the contralateral superior colliculus of some mammals. Brain Res 1974;65:343-6.

13. Lane RH, Kaas JH, Allman JM. Visuotopic organization of the superior colliculus in normal and Siamese cats. Brain Res 1974;70:413-30.

14. Weber JT, Kaas JH, Harting JK. Retinocollicular pathways in Siamese cats: an autoradiographic analysis. Brain Res 1978;148:189-96.

15. Creel D, Hendrickson AE, Leventhal AG. Retinal projections in tyrosinase-negative albino cats. J Neurosci 1982;2:907-11.

16. Guillery RW, Hickey TL, Kaas JH, Felleman DJ, Debruyn EJ, Sparks DL. Abnormal central visual pathways in the brain of an albino green monkey (Cercopithecus aethiops). J Comp Neurol 1984;226: 165-83.

17. Guillery RW. Visual pathways in albinos. Sci Am 1971; 230:44-54.

18. Hubel DH, Wiesel TN. Aberrant visual projections in the Siamese cat. J Physiol (Lond) 1971;218:33-62.

19. Hogan D, Garraghty PE, Williams RW. Unilateral misrouting at the chiasm associated with disrupted lamination of the geniculate and a vertical inversion of the visual map in area 17. Soc Neurosci Abstr 1995; 21:394.

20. Guillery RW, Casagrande VA, Oberdorfer MD. Congenitally abnormal vision in Siamese cats. Nature 1974;252:195-9.

21. Shatz C. A comparison of visual pathways in Boston and Midwestern Siamese cats. J Comp Neurol 1977; 171:205-28.

22. Cooper ML, Blasdel GG. Regional variation in the representation of the visual field in the visual cortex of the Siamese cat. J Comp Neurol 1980;193:237-53.

23. Guillery RW. An abnormal retinogeniculate projection in Siamese cats. Brain Res 1969;14:739-41.

24. Kinnear PE, Jay B, Witkop CJ Jr. Albinism. Surv Ophthalmol 1985;30:75-101.

25. Collewijn H, Apkarian P, Spekreijse H. The oculomotor behaviour of human albinos. Brain 1985;108:1-28.

26. Apkarian P, Dell'Osso LF, Ferraresi A, van der Steen J. Ocular motor abnormalities in human achiasmatic syndrome. Invest Ophthalmol Vis Sci 1994; 35(suppl):1410.

27. Dell'Osso LF, Williams RW. Ocular motor abnormalities in achiasmatic mutant Belgian sheepdogs: unyoked eye movements in a mammal. Vision Res 1995:35:109-16.

28. Apkarian P, Reits D, Spekreijse H, van Dorp D. A decisive electrophysiological test for human albinism. Electroencephalogr Clin Neurophysiol 1983;55:513-31.

29. Apkarian P. A practical approach to albino diagnosis. VEP misrouting across the age span. Ophthalmic Paediatr Genet 1992;13:77-88.

30. Apkarian P, Shallo-Hoffmann J. VEP projections in congenital nystagmus; VEP asymmetry in albinism: a comparison study. Invest Ophthalmol Vis Sci 1991;32: 2653-61.

31. Chang Chui H, Damasio AR. Human cerebral asymmetries evaluated by computed tomography. J Neurol Neurosurg Psychiatry 1980;43:873-8.

32. Weinberger DR, Luchins, DJ, Morihisa J, Wyatt RJ. Asymmetrical volumes of the right and left frontal and occipital regions of the human brain. Neurology 1982;11:97-100.

33. Grabowska A, Herman A, Nowicka A, Szatkowska I, Szelag E. Individual differences in the functional asymmetry of the human brain. Acta Neurobiol Exp 1994;54:155-62.

34. Little WS. Absence of the optic chiasm and other cerebral commissures; temporal hemianopia. Trans Am Ophthalmol Soc 1886;22:367-9.

35. Roessmann U. Septo-optic dysplasia (SOD) or DeMorsier syndrome. J Clin Neuro-ophthalmol 1989; 9:156-9.

36. Rubinstein D, Youngman V, Hise JH, Damiano TR. Partial development of the corpus callosum. Am J Neuroradiol 1994;15:869-75.

37. Dutton JJ. Gliomas of the anterior visual pathway. Survey Ophthalmol 1994;38:427-52.

38. Polyak S. The vertebrate visual system. Chicago: The University of Chicago Press, 1957.

39. Fisher NF, Jampolsky A, Scott AB. Traumatic bitemporal hemianopsia. Part I. Diagnosis of macular splitting. Am J Ophthalmol 1968;65:237-42.

40. Lehmann D, Kavanagh RN, Fender DH. Field studies of averaged visually evoked EEG potentials in a patient with a split chiasm. Electroencephalogr Clin Neurophysiol 1969;26:193-9.

41. Cohn R. Some characteristics of the cortical potential fields of the optic chiasm-sectioned cat. Electroencephalogr Clin Neurophysiol 1969;26:280-7.

42. Lehman RAW, Spencer DD. Mirror-image shape discrimination: interocular reversal of responses in the optic chiasm sectioned monkey. Brain Res 1973;52: 233-41.

43. Elekessy EI, Campion JE, Henry GH. Differences between the visual fields of Siamese and common cats. Vision Res 1973;13:2533-43.

44. Guillery RW, Casagrande VA. Studies of the modifiability of the visual pathways in Midwestern Siamese cats. J Comp Neurol 1977;174:15-46.

45. Guillery RW. Why do albinos and other hypopigmented mutants lack normal binocular vision, and what else is abnormal in their central visual pathways? Eye 1996;10:217-21.

46. Apkarian P, Reits D. Global stereopsis in human albinos. Vision Res 1989;29:1359-70.

47. Charman WN, Jennings JAM. Recognition of TNO stereotest figures in the absence of true stereopsis. Optometry Vision Sci 1995;72:535-6.

48. Fox R, Lehmkuhle S, Leguire LE. Stereoscopic contours induce optokinetic nystagmus. Vision Res 1978;18:1189-92.

49. Archer SM, Miller KK, Helveston EM. Stereoscopic contours and optokinetic nystagmus in normal and stereoblind subjects. Vision Res 1987;27:841-4.

50. Cool SJ, Crawford MLJ. Absence of binocular coding in striate cortex units of Siamese cats. Vision Res 1972;12:1809-14.

51. Marzi CA, Simoni A, Di Stefano M. Lack of binocularly driven neurons in the Siamese cat's visual cortex does not prevent successful interocular transfer of visual form discriminations. Brain Res 1976; 105:353-7.

52. Packwood J, Gordon B. Stereopsis in normal domestic cat, Siamese cat, and cat raised with alternating monocular occlusion. J Neurophysiol 1975;38:1485-99.

53. Antonini A, Berlucchi G, Di Stefano M, Marzi CA. Differences in binocular interactions between cortical areas 17 and 18 and superior colliculus of Siamese cats. J Comp Neurol 1981;200:597-611.

54. Diao Y-C, Wang Y-K, Pu M-L. Binocular responses of cortical cells and the callosal projection in the albino rat. Exp Brain Res 1983;49:410-8.

55. Blakemore C. Binocular depth discrimination and the 
nasotemporal division. J Physiol (Lond) 1969;205: 471-97.

56. Berlucchi G, Rizzolatti G. Binocularly driven neurons in visual cortex of split-chiasm cats. Science 1968;159: 308-10.

57. Blakemore C. Binocular depth perception and the optic chiasm. Vision Res 1970;10:43-7.

58. Mitchell DE, Blakemore C. Binocular depth perception and the corpus callosum. Vision Res 1970;10:49-54.

59. Cowey A, Porter J. Brain damage and global stereopsis. Proc R Soc Lond B 1979;204:399-407.

60. Zeki S, Fries W. A function of the corpus callosum in the Siamese cat. Proc R Soc Lond B 1980;207:249-58.

61. Timney B, Elberger AJ, Vandewater ML. Binocular depth perception in the cat following early corpus callosum section. Exp Brain Res 1985;60:19-26.

62. Lepore F, Ptito M, Lassonde M. Stereoperception in cats following section of the corpus callosum and/or the optic chiasma. Exp Brain Res 1986;61:258-64.

63. Innocenti GM, Frost DO, Illes J. Maturation of visual callosal connections in visually deprived kittens: a challenging critical period. J Neurosci 1985;5:255-67.

64. Elberger AJ, Smith EL III. The critical period for corpus callosum section to affect cortical binocularity. Exp Brain Res 1985;57:213-23.

65. Apkarian P, Bour L, Bruno P, Berg vd AV. Three dimensional eye movement recordings in non-decussating retinal fugal fibre syndrome: an inborn achiasmatic malformation identified with congenital and see saw nystagmus. Invest Ophthalmol Vis Sci 1995; 36(Suppl):175.

66. Dell'Osso LF, Daroff RB. Congenital nystagmus waveforms and foveation strategy. Doc Ophthalmol 1975;39:155-82.

67. Maddox EE. See-saw nystagmus with bitemporal hemianopia. Proc R Soc Med 1914;7:12-3.

68. Arnott EJ. Vertical see-saw nystagmus. Trans Ophthalmol Soc UK 1964;84:251-7.

69. Daroff RB. See-saw nystagmus. Neurology 1965;15: 874-7.

70. Nakada T, Kwee IL. Seesaw nystagmus. Role of visuovestibular interaction in its pathogenesis. J Clinical Neuro-ophthalmol 1988;8:171-7.

71. Schmidt D, Kommerell G. Congenitaler Schaukelnystagmus (seesaw nystagmus). Graefes Arch Klin Exp Ophthalmol 1974;191:265-72.

72. Zelt RP, Biglan AW. Congenital seesaw nystagmus. J Pediatric Ophthalmol Strabismus 1985;22:13-6.

73. Apkarian P. Albinism. In: Heckenlively JR, Arden GB, editors. Principles and practice of clinical electrophysiology of vision. St Louis: Mosby/Year Book, 1991:773-82. 